\title{
Mejora de la competencia literaria con un club de lectura escolar
}

Carmen Álvarez-Álvarez

Rocío Vejo-Sainz

Universidad de Cantabria - UNICAN, España

CASE REPORT

\begin{abstract}
Resumen
Algunos centros educativos que buscan hacer una mejor animación a la lectura ponen en funcionamiento clubs de lectura escolares, sin embargo, esta práctica sigue siendo minoritaria en el contexto de las acciones que los centros implementan para mejorar la competencia lectora de los alumnos. En este artículo se analiza etnográficamente el aporte que ha hecho un club de lectura escolar a la mejora de la competencia literaria de sus participantes a lo largo del primer curso académico que se pone en funcionamiento. Los resultados muestran que los miembros del club han aumentado la comprensión lectora, la educación en valores y el gusto por la lectura. Es posible concluir que la puesta en marcha de un club de lectura en la escuela permite mejorar la competencia literaria de los niños participantes.
\end{abstract}

Palabras clave:

Animación lectora; Biblioteca escolar; Competencia literaria; Interacción

\section{Improving literary competence with a school reading club}

\begin{abstract}
Some schools that are looking forward to promote a better reading encouragement create scholar-reading clubs. However, this practice is still minority in the context of actions implemented by the centers to improve the students' reading skills. This article analyzes ethnographically the contribution made by a scholar-reading club to improve the literary skills of its participants during the first academic year in that it starts up. The results show that the club members have increased their reading comprehension, values education and the pleasure of reading. It can be conclude that the creation of a reading club at school improves literary competence of participating children.
\end{abstract}

Keywords

Interaction; Literary competence; Reading encouragement; School library

\section{Introducción}

La competencia literaria se entiende como un componente de la competencia comunicativa que incluye la capacidad de leer, comprender, interpretar y valorar distintos tipos de textos literarios, disfrutar con su audición o lectura, desarrollar la imaginación, creatividad y sensibilidad estética, así como la capacidad para crear, recrear y producir textos literarios, tanto en forma oral como escrita (Prado, 2004).

La competencia literaria se vincula estrechamente con la lectura, de modo que leer es la actividad de base para la construcción de la competencia literaria (Cerrillo, 2010). En ese sentido, leer quiere decir comprender, interpretar y valorar el mensaje en sí mismo, pero el proceso de lectura culmina en la interpretación y la acción de valorar. De este modo, desarrollar la competencia literaria es una actividad compleja porque requiere necesariamente comprender, integrar e interpretar los componentes del discurso literario. Formar y desarrollar la competencia literaria será, pues, saber formar lectores que, autónomamente, gocen de los textos para llegar a establecer valoraciones e interpretaciones (Cantero \& Mendoza, 2003). Una actividad que puede ayudar a potenciar el desarrollo de la competencia literaria son los clubs de lectura. 
Los primeros clubs de lectura en España surgieron a mediados de los años ochenta y se desarrollaron sobre todo en las bibliotecas públicas, dirigiéndose mayoritariamente a personas adultas. Sin embargo, su éxito generó que los mismos fueran creciendo y diversificándose. Hoy día hay clubs de lectura en diversidad de espacios: escuelas de adultos, centros educativos de Educación Infantil y Primaria, centros penitenciarios, asociaciones, empresas privadas, etc. (Arana \& Galindo, 2009).

Tanto la investigación nacional como la internacional han venido poniendo de manifiesto las enormes posibilidades que ofrecen los clubs de lectura, en sus múltiples formas, para la mejora del gusto por la lectura y la potenciación del hábito lector (McMahon, 1992; Goatley, Brock \& Raphael, 1995; Johnsson-Smaragdi \& Jönsson, 2006; Whittingham, \& Huffman, 2009; Hill, 2012; Kim \& Quinn, 2013; Álvarez, 2015). Esto se logra porque la lectura transciende el consumo particular de libros en el ámbito privado para pasar a ser además un proceso intersubjetivo de diálogo que permite apropiarse mejor de los textos y profundizar más en sus interpretaciones (Atwell, 2007; McKool, 2007; Barone, 2011; Gambrell, 2011; Reznitskaya, 2012).

Los clubs de lectura, en sus diversas manifestaciones, han logrado dinamizar bibliotecas y promover el gusto por los libros en personas de diferentes trayectorias, logrando incluso en ocasiones que lean personas que no tenían el hábito lector desarrollado (Kong y Fitch, 2003). También han logrado el disfrute literario de muchas personas en su tiempo de ocio, favoreciendo el disfrute con las historias reales o de ficción, desarrollando la comprensión y la reflexión en profundidad sobre los temas abordados, y generando un criterio literario propio (Beach y Steven, 2011). Asimismo, mantener procesos de diálogo, discusión y argumentación de opiniones en torno a obras intensifica la comprensión lectora individual y grupal, y estimula el gusto por la lectura y los libros (Gritter, 2011; Reed \& Vaughn, 2012).

Si bien la investigación sobre clubs de lectura en el panorama internacional es amplia, la realizada sobre los clubs de lectura escolares es más reducida (Kong \& Fitch, 2003; Johnsson-Smaragdi \& Jönsson, 2006; Barone, 2011; Gritter, 2011; Oszakiewski y Spelman, 2011; Reed \& Vaughn, 2012; Gardiner, Cumming-Potvin \& Hesterman, 2013) y en el caso concreto de España, es aún incipiente (Álvarez \& Gutiérrez, 2013; Moral \& Arbe, 2013; Álvarez \& Pascual, 2014).

Tanto en el ámbito nacional como internacional, los clubs de lectura desarrollados en las diferentes escuelas se caracterizan por su enorme diversidad: edad/es a las que se dirigen, participación o no de familias, selección de las obras, tiempos para reunirse, etc. En función de los objetivos del proyecto, la formación de los mediadores, la implicación del profesorado, el interés de la escuela, etc. caben muchas posibilidades. En todo caso, en los clubs de lectura escolares el proceso suele ser el siguiente: se selecciona un libro, se determina un tiempo para su lectura y se fija una reunión para comentar la obra. En estas reuniones se suelen abordar pasajes destacados del libro, se cuestionan comportamientos de los protagonistas, se plantean experiencias personales, se ofrecen pensamientos y reflexiones, etc. (Álvarez \& Gutiérrez, 2013). En todo caso, los clubs de lectura analizados desde la investigación ofrecen resultados muy positivos que hacen pensar que esta práctica puede ser bastante relevante en el desarrollo y mejora de la competencia literaria.

El estudio de Oszakiewski y Spelman (2011), comprobó que los lectores jóvenes que hablan de sus libros y preferencias se van haciendo cada vez más competentes y pueden participar en sesiones para discutir libros hablando de sus sentimientos, mostrando su opinión sobre los textos, aportando informaciones sobre el carácter o estilo del autor o sobre el vocabulario, desarrollándose académicamente, literariamente y lingüísticamente.

De hecho, la investigación de Burbank, Kauchak y Bates (2010), realizada con profesorado, ha demostrado que un club de lectura puede ser un mecanismo para la formación y el desarrollo profesional de los maestros en formación y en ejercicio, a la par que proporciona elementos para repensar la acción docente propia para hacerla más democrática y deliberativa (Gardiner, Cumming-Potvin \& Hesterman, 2013).

El estudio de Hill (2012), concluye que los clubs de lectura pueden ser un complemento a las prácticas lectoras habituales del currículum, al facilitar habilidades de escuchar y hablar, elaborar interpretaciones diversas sobre los textos y plantear preguntas y respuestas críticas sobre la literatura. Para que esto sea así, los estudios han planteado la relevancia de contar con un docente-mediador o animador a la lectura formado en la materia (Shaw, 2013).

Además, la interacción del grupo y la escucha a los compañeros favorece la implicación personal de los participantes, desarrolla el sentimiento de grupo y un clima más estimulante como consecuencia de que los alumnos se sienten escuchados, conocidos y respetados, y el desarrollo de discusiones que ayudan a conectar la literatura con la vida (Gritter, 2011; Kent \& Simpson, 2012). 
Es por ello que en este estudio hemos tratado de comprobar si un club de lectura escolar puede suponer un estímulo a la mejora de la competencia literaria infantil: si desarrolla habilidades expresivas, habilidades cognitivas y de comprensión lectora, si desarrolla axiológica y emocionalmente a los niños y si provoca actitudes favorables hacia la literatura.

\section{Método}

\subsection{Estudio de caso}

Para saber si los clubs de lectura escolares estimulan la competencia literaria es posible seguir numerosos enfoques metodológicos. En esta investigación hemos optado por realizar un estudio de caso en un nuevo club de lectura escolar dirigido a quinto y sexto curso de Educación Primaria de un centro concertado cántabro urbano que ofrecía numerosas actividades extraescolares diarias de diverso tipo (idiomas, deportes, etc.) y el club de lectura pasó a ser una más, resultando imposible en este primer año situarlo en el calendario sin que se solapase con las que ya tenían una amplia trayectoria. La ausencia de centros escolares que implementen esta innovadora estrategia de animación lectora ha impedido el estudio de más casos.

El estudio de caso es la forma de investigación propia de la metodología cualitativa, al no realizar muestreos para seleccionar a los participantes de la investigación, sino, elegir contextos concretos relevantes para la exploración de fenómenos desde dentro; sobre todo, cuando parece que el objeto de observación está generando un cambio significativo con respecto al desarrollo escolar convencional. Tal es el caso del centro elegido: se inicia por primera vez un club de lectura escolar, pero su creación es bien acogida por parte de la escuela, las familias y el alumnado.

La hipótesis de esta investigación es que un club de lectura escolar puede contribuir a mejorar la competencia literaria del alumnado participante y el propósito de este estudio es determinar en qué aspectos concretos puede lograrlo (habilidades expresivas, habilidades cognitivas y de comprensión lectora, habilidades axiológicas y emocionales y actitudes favorables hacia la literatura).

Para ello, se han grabado en audio las seis reuniones realizadas en la primera edición de este club de lectura escolar y se han transcrito todas las interacciones mantenidas entre sus miembros. Esta información ha permitido acceder a los debates de los participantes y la categorización de la misma ha contribuido a valorar su aporte a la mejora de la competencia literaria. El análisis de los datos se ha realizado siguiendo pautas propias del análisis de contenido.

\subsection{El caso: participantes, obras literarias y procedimiento}

En esta experiencia piloto el grupo estaba formado por seis niñas y tres niños, de edades comprendidas entre los once y los trece años, que asistían voluntariamente, a excepción de dos casos (que lo hacían por deseo de sus familias). Se trataba de un grupo heterogéneo en nivel lector y motivación por la lectura.

La coordinadora (una especialista en literatura infantil y juvenil) hizo una selección inicial de obras y las lecturas a realizar. Finalmente, se determinaron en acuerdo con el alumnado, teniendo en cuenta los fondos disponibles en la biblioteca escolar. Fueron las siguientes:

\begin{tabular}{|l|l|l|}
\hline \multicolumn{1}{|c|}{ Obra } & \multicolumn{1}{|c|}{ Autor } & \multicolumn{1}{c|}{ Síntesis } \\
\hline Ojo de Nube & $\begin{array}{l}\text { Ricardo } \\
\text { Gómez }\end{array}$ & $\begin{array}{l}\text { En la tribu de los crow todos aportan algo: fuerza, destreza, valentía... Ojo de } \\
\text { Nube, un chico ciego, parece ser el que menos puede contribuir a la } \\
\text { comunidad, pero demostrará tener otras habilidades irreemplazables y muy } \\
\text { positivas para su tribu. }\end{array}$ \\
\hline $\begin{array}{l}\text { Las vacaciones } \\
\text { del pequeño } \\
\text { Nicolás }\end{array}$ & $\begin{array}{l}\text { René } \\
\text { Goscinny }\end{array}$ & $\begin{array}{l}\text { Nicolás, el joven y escéptico protagonista, pone en evidencia, con ironía y } \\
\text { amabilidad, las absurdas leyes que rigen el mundo de los adultos a partir de } \\
\text { la narración de sus aventuras en sus vacaciones de verano, en la playa y en } \\
\text { un campamento. }\end{array}$ \\
\hline
\end{tabular}

Tabla 1. Lecturas realizadas en el club de lectura objeto de estudio (Continua). 


\begin{tabular}{|l|l|l|}
\hline \multicolumn{1}{|c|}{ Obra } & \multicolumn{1}{|c|}{ Autor } & \multicolumn{1}{c|}{ Síntesis } \\
\hline $\begin{array}{l}\text { James y el } \\
\text { melocotón } \\
\text { gigante }\end{array}$ & Roald Dahl & $\begin{array}{l}\text { James es un niño huérfano que vive con dos tías muy severas que le hacen } \\
\text { la vida imposible. Pero un día, un extraño personaje le regala unas bolitas } \\
\text { mágicas que hacen crecer sorprendentemente el melocotonero. Montado en } \\
\text { un melocotón gigante, James inicia un viaje fascinante por el mundo entero. }\end{array}$ \\
\hline $\begin{array}{l}\text { Konrad, el niño } \\
\text { que salió de una } \\
\text { lata de } \\
\text { conservas }\end{array}$ & $\begin{array}{l}\text { Christine } \\
\text { Nöstlinger }\end{array}$ & $\begin{array}{l}\text { La señora Bartolotti pide tantos objetos por catálogo que no sabe cómo } \\
\text { actuar cuando una fábrica le hace llegar una gran lata con un niño perfecto, } \\
\text { educado, amable, listo y obediente dentro. Ella no lo pidió, pero empiezan a } \\
\text { convivir hasta que los encargados de la fábrica se dan cuenta del error del } \\
\text { envío e intentan recuperar a Konrad. }\end{array}$ \\
\hline Matilda & Roald Dahl & $\begin{array}{l}\text { Matilda es una lectora empedernida con solo cinco años. Sensible e } \\
\text { inteligente, todos la admiran menos sus mediocres padres, que la consideran } \\
\text { una inútil. Además, tiene poderes extraños y maravillosos... Un día, Matilda } \\
\text { empieza a emplearlos contra la abominable y cruel directora de su escuela. }\end{array}$ \\
\hline
\end{tabular}

Tabla 1. Lecturas realizadas en el club de lectura objeto de estudio (Final).

En diciembre de 2014 se realizó una reunión de constitución del club y se entregó el libro de la primera lectura. Se han realizado encuentros mensuales para comentar las sucesivas obras (de enero a mayo de 2015). La coordinadora pidió a los niños que pensasen para cada reunión aquello que más les hubiera llamado la atención de la obra para compartirlo con los/as compañeros/as. A partir de sus reflexiones se promovieron los debates literarios. En la última parte de la reunión se iniciaba la lectura de los primeros capítulos de la siguiente obra a leer y se empezaba a reflexionar sobre la misma, generándose hipótesis de lectura que serían verificadas en la siguiente reunión. Casi todos los niños optaron por leer en casa el libro en solitario, sin ayuda de la familia.

\section{Resultados}

La transcripción de las grabaciones de las reuniones del club de lectura seleccionado ha permitido realizar un análisis de contenido de las tertulias, demostrando que este club ha posibilitado el cultivo de al menos cuatro aspectos ligados a la competencia literaria: (1) la comprensión lectora, (2) la educación emocional y en valores, (3) el enjuiciamiento literario y (4) el disfrute con la literatura. Para dar cuenta de algunos debates registrados se emplean las siglas "C" y "A" para identificar las interacciones de coordinadora y alumnado.

\subsection{Comprensión lectora}

La participación en el club de lectura permitió -entre otros aspectos- que los alumnos pudieran "socializar" la comprensión lectora de las obras tras la realización de la lectura individual. Al poder contrastar con los compañeros sus interpretaciones sobres los textos leídos y compartir dudas sobre pasajes o aspectos ambiguos, los niños realizaron una comprensión más profunda y más fundamentada de las obras.

El análisis de la mayor parte de los acontecimientos que narran las obras ha sido objeto de diálogo en el club, de modo que los participantes han reflexionado sobre el contenido de la obra y en los debates han demostrado haberlo entendido. Puede servir como ejemplo de este hecho las siguientes interacciones en que se está profundizando sobre un pasaje de Las vacaciones del pequeño Nicolás, demostrando que han entendido el sentimiento que guía el comportamiento del protagonista.

C: A veces somos muy exagerados cuando contamos las cosas a la gente. Parece que cuanto menos fiel eres a la verdad, mejor.

A1: Sí, y luego al final cuando le contó sus vacaciones a la niña... ahí ¡vamos que si lo exageró!

C: ¿Y por qué lo exageró tanto?

A2: Porque la niña le dijo que estuvo en las vacaciones con otro niño en la playa. [...] 


\section{C: ¿Le gustaba la niña?}

A2: Sí, dijo que es muy morena y tiene los ojos azules.

A1: Le dio envidia que el otro niño se lo hubiera pasado mejor que él y que estuviera con ella.

C: Le dio envidia, ¿no? Que la niña se lo hubiese pasado bien en las vacaciones con otro niño que no fuese él.

A3: Le come la envidia.

El comentario de gran número de pasajes relevantes en cada obra leída revela una comprensión de los principales momentos de las historias. Sin embargo, también ha sucedido que en tres ocasiones algunas partes de las obras no fueron bien comprendidas en el proceso de lectura solitaria, siendo luego en la reunión fuente de debate y esclarecimiento. La primera sucedió con el final de la historia de Ojo de Nube: los niños habían interpretado un final feliz para los crow, al no captar el mensaje del párrafo final en el que el autor pone de manifiesto que esa y otras tribus desaparecen.

\section{C: ¿Y cómo termina el libro?}

A1: Los indios se quedan con los caballos y al final desarrollan un estilo de vida para no traspasar las montañas y Halcón Pequeño sobrevivió, aunque decía que iba a morir.

A2: Se meten en una cueva con los caballos. Lo que le pasa a Ojo de Nube es que le dan dos plumas que significan valentía o algo así.

A3: Ojo de nube acaba siendo jefe ¿no?

$[\ldots]$

C: ¿Cómo termina el libro? A leer el final de nuevo y pensar todos en eso. ¿No lo habéis entendido?

A1: Pues no mucho, la verdad.

C: Dice: "Los mala cosa siguieron avanzando y apropiando de las tierras de los Osaje, de los Toncawa, de los Siuk, de los Dakota, de los Cherookees..." ¿Qué pasa con los Mala Cosa? Que acaban con todo.

A4: Ah claro, o sea que acaba mal.

C: ¿No lo habíais entendido?

A4: No.

A5: Acaba mal el libro.

C: Acaba como acaba la realidad. Lo que tenemos hoy en día, que apenas quedan unos poquitos en algunos poblados. ¿Quiénes acabaron con estas poblaciones?

A3: Los Mala Cosa. El hombre blanco. O sea, nosotros.

C: ¡Así termina el libro!

A3: Pues no me había enterado.

A2: Ni yo.

La segunda ocasión en que algún pasaje de la obra no se entendió bien fue con el libro de James y el Melocotón Gigante. Algunos de los niños no se habían dado cuenta de que James en el viaje a bordo del melocotón cambia de continente.

A1: Eso lo decían cuando ya estaban llegando al Empire State Building.

C: Por cierto, el viaje es desde el Reino Unido hasta Estados Unidos. 
A2: Sí.

C: Han atravesado todo el Océano Atlántico.

A3: Yo creo que sí.

C: Efectivamente. Sus padres vivían en Londres. El viaje que hacen en el melocotón es a través de todo el Océano Atlántico, ¿eso lo habíais pensado?

$[\ldots]$

A4: No lo ponía.

C: Así no, pero si están en Londres y van por el mar, por el mar, por el mar... y llegan al Empire State Building...

La tercera ocasión en que una obra no fue bien comprendida sucedió al inicio de la tertulia de Konrad, el niño que salió de una lata de conservas, porque para un niño no estaba claro si la señora había adoptado al niño o simplemente se quedaba con él sin adoptarlo.

A1: Pero ¿cómo es? ¿La señora lo adopta?

A2: El niño llegó a su casa, ¿no? y ella no sabía cómo había llegado porque no lo encargó.

A1: Es que lo leí, pero no lo entendí.

C: ¿Qué es lo que no entendiste? Que te lo explicamos.

A1: La parte que dice mi compañera no la he entendido. No entiendo si la señora que recibe el pedido lo adopta.

C: Sí, pasa a ser su madre.

A1: Ah, vale.

El hecho de que en las tertulias se vuelva sobre los principales momentos de las obras y que aparezcan algunas situaciones de falta de comprensión da valor y riqueza a las reuniones mantenidas. En este ambiente de participación los niños muestran una mayor implicación por clarificar sus dudas y por aportar y compartir con los demás sus interpretaciones.

\subsection{Educación emocional y en valores}

En el comentario de todas las obras los/as niños/as han manifestado numerosas emociones que las historias les han provocado y han emitido juicios de valor sobre los diferentes mensajes que los autores trasmiten en los libros, originándose en contadas ocasiones algunos pequeños debates entre compañeros/as. Las interacciones siguientes, respecto a la familia de Matilda, son ilustrativas del tipo de sentimientos y emociones que algunas ideas mostradas en las obras promueven en los niños/as. En este caso, los participantes coinciden en despreciar el comportamiento del padre de la niña protagonista, con la que han empatizado desde el inicio de la obra, y hablan del valor de la honestidad.

A1: A mí lo que menos me gusta del libro es que los padres timan a la gente.

A2: Meten serrín a los motores de los coches que venden y les quitan kilómetros con un destornillador eléctrico, creo que era.

A3: Y le enseña a su hijo eso.

A1: Le ponen kilómetros para venderlo mejor.

A2: ¡Le quitan!

A1: Eso, le quitan. 
C: A mí tampoco me ha gustado que el padre fuese tan poco honesto con la gente.

A4: Y encima le enseña a su hijo todo lo que hace. $Y$ luego la Trunchbull va donde Matilda y le dice: "Tu padre me ha engañado, puso serrín en el motor de mi coche".

Han sido identificados otros veinticuatro momentos de enjuiciamiento de las obras de los que no es posible dar cuenta por razones de espacio. Esto pone de manifiesto que las obras de literatura seleccionadas les han conmovido y les han provocado reflexiones respecto a valores. Algunas de ellas están más alejadas de sus vidas, como la que se ha recogido anteriormente, y otras están más próximas, como la siguiente, en la que reflexionan sobre la amistad y la libertad comentando el desenlace del libro de James y el melocotón gigante.

A1: A mí me gustó mucho el final porque James había estado siempre muy solo y ahora tenía amigos y les podía contar sus cosas.

C: Pues sí, le cambio la vida radicalmente, porque siempre estaba aburrido, llorando y triste...

A2: ¡Y pasa ahora a tener mogollón de amigos!

C: Pasa a estar viviendo dentro de la pepita del melocotón. Era su casa, ¿no?

Alumnos/as: Sí.

A3: Hay una imagen en la que se ve la pepita.

A4: Yo creo que viene textualmente también.

A3: Vive dentro del hueso del melocotón.

$[\ldots]$

C: Al final todos han tenido suerte, no solo James, porque los otros amigos también se dedican a lo que quieren...

A1: Han sido famosos y héroes, cada uno luego realmente ha hecho lo que ha querido.

\subsection{Enjuiciamiento literario}

En el club de lectura objeto de análisis el alumnado ha realizado observaciones relativas a diversos aspectos de las obras literarias: expresión, estrategias literarias empleadas por los autores, ilustraciones, preferencias lectoras, etc. Este hecho pone de manifiesto que el club de lectura escolar puede abrir un espacio de debate donde es posible iniciarse en la crítica literaria. En la siguiente interacción cuestionan la prosa poco ágil de René Goscinny, al reiterar mucho en el uso de algunas expresiones.

A1: No me gustó que decía que era un niño muy bruto. Lo decía tantas veces que me aburría.

C: Que era un burro, ¿quieres decir?

A1: Sí, eso. Decía que es muy burro entre paréntesis todo el rato.

C: Mamerto.

A1: Sí, ese, Mamerto. "Mamerto, el burro".

A2: Nicolás dice mucho la frase de: "es de lo más genial..." porque el monitor también decía eso y con otras cosas también.

C: ¿Era como una muletilla para él?

A2: Sí, lo decía mucho. 
También han cuestionado la calidad y cantidad de imágenes de todas las obras leídas, como puede verse en el siguiente debate, con el primer libro leído, el de Ojo de Nube, en que además escogen su favorita razonando el porqué. Además, en estas interacciones también cuestionan la edad a la que se pueden dirigir los libros y su interés, formulando hipótesis de lectura.

C: ¿Qué os han parecido las ilustraciones?

A1: Había muy pocas, había cuatro.

C: Muy pocas, ¿os gusta que los libros tengan más ilustraciones?

A2: No. Mira, el del Pequeño Nicolás está bien de ilustraciones.

A1: Sí.

C: Tiene muchos más dibujitos, sí.

A3: Y está más guay.

A4: El del Pequeño Nicolás es para más pequeños.

C: ¿Tú crees que ese va a estar más guay?

A3: Sí, porque he leído un poquito, algunas páginas, y parece que está súper guay.

C: ¿Cuál ha sido la ilustración que más os ha gustado del libro?

A3: A mí la de los caballos.

A2: A mí la de la madre. Sí, la del niño con la madre.

C: ¿A ti por qué te ha gustado esa?

A2: Porque se le ven los ojos, y es muy cuqui.

C: ¿Sí? ¿Te parece cuqui así con los ojos blancos?

A2. Sí.

A3: Yo monto a caballo y entonces me gustan los caballos. A mí los caballos me gustan mucho.

C: A ti, ¿cuál fue la ilustración que más te gustó?

A5: Ésta. Porque hay muchas muertes.

C: ¿Y a ti?

A6: Ésta, que le dibujan sobre el vientre, porque es la parte en que le enseñan todas las cosas y así le muestran cómo lo hace.

A7: A mí me gusta también esa.

En el club de lectura también hablan entre pares de sus preferencias lectoras, haciéndose notar en pocos casos la existencia de cierto hábito lector, ligado a literatura infantil comercial o reducido a las obras obligatorias que propone la escuela.

A1: Un niño me dijo que el que están leyendo para clase no le está gustando, eso dice.

C: ¿El de La isla del tesoro?

A1: Sí.

A2: Yo creo que de La isla del tesoro hay varias versiones porque Jerónimo ha hecho uno de La isla del tesoro.

A3: También hizo uno de La vuelta al mundo en ochenta días.

C: El original es de Julio Verne. 
A3: Ya, pero también han hecho una adaptación en Jerónimo.

A4: Yo, el libro que menos me gusta es uno de Harry Potter. Me parecía súper aburrido.

A5: A mi Harry Potter no me gusta nada.

C: Pues hay muchos niños a los que les gusta Harry Potter.

A3: Ya, pero a mí no me llama. A mí me gustó Jerónimo Stilton hasta los ocho años.

C: ¿Qué tipo de libros os gustan?

A4: A mí me gusta El diario de Nick y estoy leyendo La reina de cristal, el primer libro.

A6: Yo me estaba leyendo uno de romanos, pero ya no, lo perdí.

\subsection{Disfrute con la literatura}

El último aspecto que destacaremos en relación con la mejora de la competencia literaria que favorece este club es el disfrute literario. Sin embargo, no por recogerlo el último éste es un aspecto poco desarrollado, al contrario. Se han identificado cuarenta y tres momentos de interacción (que no es posible recoger en un artículo de estas características) en los que los participantes han puesto de manifiesto ganas de leer y curiosidad por las historias, un aumento de su autoestima lectora, la satisfacción de sus familias con esta experiencia, el desarrollo de una lectura más reflexiva y placentera que supera rutinas lectoras previas y un mayor deseo de leer en voz alta y hablar de libros con otras personas.

En la primera reunión, desde el inicio, hubo testimonios que pusieron de relieve la buena acogida del club de lectura y la motivación lectora: leyeron Ojo de Nube con entusiasmo desde que se les entregó y dos niños no pudieron resistirse a empezar el siguiente libro propuesto, como puede verse en la siguiente transcripción.

\section{A1: Yo en la primera semana ya me lo acabé. \\ C: ¿Sí? ¿Tú en una semana te lo leíste ya? ¡Qué rápido!}

A1: Y aquí ya voy por la mitad.

C: Ah, ¿sí? ¿Ya lo has empezado también? Bueno había que esperarse un poquito.

A2: Yo ya me he leído la primera página del siguiente. Está muy guay.

En todas las tertulias se produjeron interacciones que revelan motivación lectora, reflexión personal sobre las obras y gusto por la lectura. Por ejemplo, en el inicio de la tertulia sobre Las vacaciones del pequeño Nicolás, otro niño nuevamente manifestó que no pudo resistirse a esperar a leer el siguiente libro acordado (Matilda). "Yo me lo he empezado a leer ayer a partir de las nueve y media de la noche. Me dije, voy a empezarlo a leer, entonces empiezo a leer y está "diver". Habla de que hay niños que se portan mal pero que sus padres... Me he leído ayer estos dos capítulos y esto me lo he leído antes mientras esperaba a mi amiga”. Avanzada la reunión, se comenzó a hablar del club de lectura, manifestando lo siguiente: una positiva valoración de las lecturas recomendadas, el agrado de pensar respuestas a las preguntas que formula la coordinadora, el aumento del hábito lector y la incorporación de la lectura como una actividad de ocio más, la positiva valoración familiar y el deseo de que en las clases escolares ordinarias de Lengua Castellana y Literatura se trabajase de este modo.

C: ¿Qué es lo que más te gusta del club de lectura?

A1: Pues que recomendáis libros y a veces dices "no me apetece leerme este" y luego lo lees y está guay el libro.

A2: A mí me gustan las preguntas que nos haces sobre el libro.

A3: A mí me gusta hablar sin levantar la mano.

C: ¿Qué es lo que más te gusta del club de lectura a ti? 
A4: Pues que nos recomendáis libros, porque yo no sé cuál coger.

C: ¿A ti?

A5: Lo de las preguntas.

Un aspecto que les ha atraído a leer en el club de lectura fue la selección de obras y las preguntas que la coordinadora formulaba a los participantes sobre los libros, las cuales se dirigían a reflexionar sobre pasajes de las historias y no a comprobar si han retenido datos y detalles del libro.

C: ¿Leéis más ahora que antes de venir al club de lectura?

Varios: Sí.

A2: Antes de dormir. Antes veía la tele, ahora leo un poquito.

C: ¿Tú también?

A6: A ver yo leía porque me gustaba, luego lo dejé un poco, y ahora lo retomé.

Estas interacciones ponen de relieve que han incorporado/retomado la lectura a su tiempo de ocio.

C: Y en casa ¿qué piensan de nuestro club de lectura?

A1: Pues que está bien.

A3: Que es bueno para mejorar la lectura.

A4: A mí me han obligado para mejorar. Yo es que antes de dormir hacía otras cosas. Jugaba, veía la tele y ahora leo.

A2: A mí porque he suspendido, aunque a mi madre le gustaría que fuese todas las semanas... no una vez al mes.

Ninguna familia ha mostrado objeciones al desarrollo de esta práctica de innovación lectora y las que facilitaron que sus hijos asistiesen valoraron muy positivamente la experiencia.

C: ¿Os gustaría que se hiciesen cosas en clase parecidas al club de lectura?

A4: Sí, porque así no tendríamos deberes...

C: ¿En clase de lengua y literatura se podría hacer algo parecido?

A5: Sí, estaría bien hacer algo así en lengua.

Estas interacciones muestran agrado con la experiencia y, en conjunto, muestran que la participación en un club de lectura escolar provoca formas positivas de relación con la literatura no experimentadas anteriormente.

\section{Conclusiones}

Este estudio confirma la relevancia que puede tener un club de lectura escolar en la mejora de la competencia literaria en, al menos, los cuatro ámbitos analizados: ha logrado estimular la comprensión literaria a través de sus procesos de diálogo (Gritter, 2011; Reed \& Vaughn, 2012), ha despertado emociones y ha incitado al debate sobre valores (Oszakiewski \& Spelman, 2011; Álvarez \& Gutiérrez, 2013; Álvarez \& Pascual, 2014), ha potenciado el enjuiciamiento literario (Beach \& Steven, 2011; Gritter, 2011; Hill, 2012; Kent \& Simpson, 2012; 
Shaw, 2013) y ha desarrollado el gusto por la lectura en tiempo de ocio y el hábito lector de los participantes (McMahon, 1992; Goatley, Brock \& Raphael, 1995; Johnsson-Smaragdi \& Jönsson, 2006; Atwell, 2007; McKool, 2007; Whittingham, \& Huffman, 2009; Barone, 2011; Gambrell, 2011; Hill, 2012; Reznitskaya, 2012; Kim \& Quinn, 2013; Álvarez, 2015). Como han planteado Ballester e Ibarra (2009), la competencia literaria se adquiere a partir de la inmersión, de la interpretación y el disfrute del texto.

Aunque el proceso de lectura individual puede resultar placentero para algunos niños, el hecho de compartir la literatura en grupo genera otras sinergias y emociones, ya que al tomar la palabra y aportar sus ideas y valores aumentan su motivación lectora (Álvarez \& Pascual, 2014). Además, a través de la interacción entre los participantes, se promueve un aumento de la comprensión lectora, de la discusión sobre valores, de la crítica literaria y del gusto por la literatura. En esta situación, es, por tanto, muy importante el papel del animador a la lectura, como ejemplo y coordinador de las interacciones, buscando el fomento del diálogo, el entendimiento y la colaboración entre todas las personas (Cerrillo, 2010; Shaw, 2013). Su función resulta indispensable para el correcto desarrollo de las dinámicas que se producen dentro de un club de lectura. Por consiguiente, es importante que los coordinadores de un club literario sepan lo que buscan, cómo provocarlo y desarrollarlo, para así, aumentar la competencia literaria infantil.

No obstante, esta investigación tiene la limitación de ser un estudio de caso único, y, por tanto, las conclusiones no pueden ser generalizables. Sin embargo, no es ese el objetivo de los estudios de caso, sino la profundización en una unidad pequeña de observación para que el lector del estudio, conociendo buenas prácticas relevantes con el mayor detalle, se interrogue sobre lo que puede hacer en su contexto, para mejorarlo. En este sentido, se ha podido corroborar el interés innegable de este tipo de prácticas de animación a la lectura.

Con esta investigación se comprueba que un club de lectura puede suponer un estímulo a la mejora de la competencia literaria infantil: desarrolla habilidades expresivas, habilidades cognitivas y de comprensión lectora, desarrolla axiológica y emocionalmente a los niños y provoca actitudes favorables hacia la literatura. Por ello, concluimos que es urgente y relevante que los centros educativos se impliquen en el desarrollo de clubs de lectura escolares ya que puede ser concebido como uno de los recursos más potentes para favorecer la innovación en la didáctica de la literatura. Asimismo, también parece necesario transformar las prácticas de trabajo literarias habituales en las aulas y bibliotecas para abordar la lectura literaria desde una perspectiva de diálogo (Hill, 2012). Como ha planteado Ballester (2015), el desarrollo de la competencia literaria exige un larguísimo proceso que comprende desde el inicio en la etapa de primeros lectores hasta la etapa de sistematización, de reflexión y de desarrollo de las capacidades metaliterarias. Resulta, por tanto, imprescindible desarrollar estrategias que permitan dotar a nuestros estudiantes de habilidades prácticas y de pensamiento crítico para interpretar los textos más allá de su significado explícito.

La investigación precedente nos hace pensar que estamos en un momento propicio para plantear proyectos innovadores que favorezcan el desarrollo de la competencia lectora y superen prácticas tradicionales habituales, que limitan el disfrute lector y el cultivo de hábitos lectores. No obstante, necesitamos más investigación y divulgación sobre los aportes que hacen y pueden hacer los clubs de lectura escolares en el contexto nacional e internacional a la mejora de la competencia literaria.

\section{Referências}

Álvarez, C. \& Gutiérrez, R. (2013). Educar en valores a través de un club de lectura escolar: un estudio de caso. Revista $\begin{array}{llll}\text { Complutense } & \text { 24(2), } & \text { 303-319. } & \text { Recuperado deción, }\end{array}$ http://revistas.ucm.es/index.php/RCED/article/download/42081/40056.

Álvarez, C. (2015). Book clubs: an ethnographic study of an innovative reading practice in Spain. Studies in Continuing Education, DOI: 10.1080/0158037X.2015.1080676

Álvarez, C. \& Pascual, J. (2014). Aportaciones de un club de lectura escolar a la lectura por placer. El profesional de la información, 23(6), 625-631. DOI: http://dx.doi.org/10.3145/epi.2014.nov.10 Recuperado de: http://www.elprofesionaldelainformacion.com/contenidos/2014/nov/10.pdf

Arana, J. \& Galindo, B. (2009). Leer y conversar. Una introducción a los clubes de lectura. Gijón: Trea.

Atwell, N. (2007). The reading zone: how to help kids become skilled, passionate, habitual, critical readers. Nueva York: Scholastic.

Ballester, J. (2015). La formación lectora y literaria. Barcelona, Graó. 
Ballester, J. \& Ibarra, N. (2009). La enseñanza de la literatura y el pluralismo metodológico. Ocnos, 5, 25-36. Recuperado de: http://www.uclm.es/cepli/v1 doc/ocnos/05/ocnos 05 cap2.pdf

Barone, D. (2011). Making meaning: Individual and group response within a book club structure. Journal of Early Childhood Literacy, 13(1), 3-25. DOI: 10.1177/1468798411430092

Beach, R. \& Steven Y. (2011). Practices of productive adult book clubs. Journal of Adolescent \& Adult Literacy, 55(2), $121-131$.

Burbank, M. D., Kauchak, D. \& Bates, A. J. (2010). Book clubs as professional development opportunities for preservice teacher candidates and practicing teachers: an exploratory study. The new educator, 6(1), 56-73.

Cantero, F.J. \& Mendoza, A. (2003). "Conceptos básicos en Didáctica de la Lengua y la Literatura. En A. Mendoza (coord.). Didáctica de la Lengua y la Literatura (pp. 33-78). Madrid: Pearson.

Cerrillo, P. C. (2010). Literatura Infantil y Juvenil y educación literaria. Recuperado de http://elibros.octaedro.com/downloadf.asp?m=10107.pdf

Gambrel, L.B. (2011). Seven rules of engagement: What's most important to know about motivation to read. The Reading

Teacher, 65(3), 172-178. $\quad$ Recuperado de: http://www.readinghalloffame.org/sites/default/files/final pdf of ms 10.1002 trtr.01024.pdf

Gardiner, V., Cumming-Potvin, W. \& Hesterman, S. (2013). Professional learning in a scaffolded 'multiliteracies book club': Transforming primary teacher participation. Issues in Educational Research, 23(3), 357-374.

Goatley, V. J., Brock, C. H. \& Raphael, T. E. (1995). Diverse learners participating in regular education "Book Clubs". Reading Research Quarterly, 30(3), 352-380.

Gritter, K. (2011). Promoting Lively Literature Discussion. The Reading Teacher, 64(6), 445-449. DOI:10.1598/RT.64.6.7 Recuperado de: http://onlinelibrary.wiley.com/doi/10.1598/RT.64.6.7/pdf

Hill, K.D. (2012). Primary Students's Book Club Participation. Language and Literacy, 14(1), 91-109.

Johnsson-Smaragdi, U. \& Jönsson, A. (2006). Book Reading in Leisure Time: Long-Term changes in young peoples' book reading habits. Scandinavian Journal of Educational Research, 50(5), 519-540. DOI: 10.1080/00313830600953600

Kent, A. \& Simpson, J. (2012). The power of literature: establishing and enhancing the young adolescent classroom community. Reading Improvement, 49(1), 28-32.

Kim, J. S., \& Quinn, D. M. (2013). The Effects of Summer Reading on Low-Income Children's Literacy Achievement From Kindergarten to Grade 8 A Meta-Analysis of Classroom and Home Interventions. Review of Educational Research, 83(3), 386431. DOI: $10.3102 / 0034654313483906$

Kong, A. \& Fitch, E. (2003). Using book club to engage culturally and linguistically diverse learners in reading, writing, and talking about Books. The Reading Teacher, 56(4), 352-362. Recuperado de: http://www.jstor.org/stable/20205209? seq=1\#page scan tab contents

Moral, A. \& Arbe, U. (2013). Una experiencia docente sobre la lectura compartida, la lectura por placer y las TICS como medio de comunicación y creatividad: Club de Lectores. Psicología Educativa, 19(2), 123-126. Recuperado de: http://pse.elsevier.es/index.php? $\mathrm{p}=$ watermark\&idApp=UINPBA00004F\&piiltem $=S 1135755$ X $13700198 \&$ origen $=p$ se $\% 20 \& w e b=\underline{p}$ se\%20\&urlApp=http://pse.elsevier.es\&estadoltem=S300\&idiomaltem=es

McKool, S. S. (2007). Factors that influence the decision to read: an investigation of fifth grade students' out-of-school reading habits. Reading improvement, 44(3), 111-131.

McMahon, S. I. (1992). Book Club: A Case Study of a Group of Fifth Graders as They Participate in a Literature-Based Reading Program. Reading Research Quarterly, 27(4), 292-294.

Prado, J. (2004). Didáctica de la lengua y la literatura para educar en el siglo XXI. Madrid: La Muralla.

Reed, D. K. \& Vaughn, S. (2012). Retell as an Indicator of Reading Comprehension. Scientific Studies of Reading, 16(3), 187217. DOI: $10.1080 / 10888438.2010 .538780$

Reznitskaya, A. (2012). Dialogic teaching. Rethinking language use during literature discussions. The Reading Teacher, 65(7), 446-456. Recuperado de: http://onlinelibrary. wiley.com/doi/10.1002/TRTR.01066/pdf

Shaw, D. M. (2013). Man's best friend as a reading facilitator. The Reading Teacher, 66(5), 365-371. DOI:10.1002/TRTR.1136 Recuperado de: http://onlinelibrary. wiley.com/doi/10.1002/TRTR.01136/pdf

Whittingham, J.L. \& Huffman, S. (2009). The effects of book clubs on the reading attitudes of middle school students. Reading Improvement, 46(3), 130-136. 


\section{Datos de las autoras}

\section{Carmen Álvarez-Álvarez}

Doctora en Pedagogía. Licenciada en Pedagogía. Graduada en Magisterio. Experta en Gestión emprendedora en Lectura y Escritura Máster en Acción Tutorial Máster en Promoción a la Lectura y Literatura Infantil.

mcalvarezalvarez@gmail.com

\section{Rocío Vejo-Sainz}

Máster en Educación Emocional, Social y de la Creatividad por la Universidad de Cantabria (UNICAN). Bachiller en Educación por la UNICAN.

rocio.vejo@alumnos.unican.es

Recibido - Received: 2016-08-30

Aceitado - Accepted: 2016-10-20

\section{(cc) EY}

This work is licensed under a Creative Commons Attribution 4.0

United States License.

\section{ULIS D-Sorke}

This journal is published by the University Library System of the University of Pittsburgh as part of its D-Scribe Digital Publishing Program and is cosponsored by the University of Pittsburgh Press. 